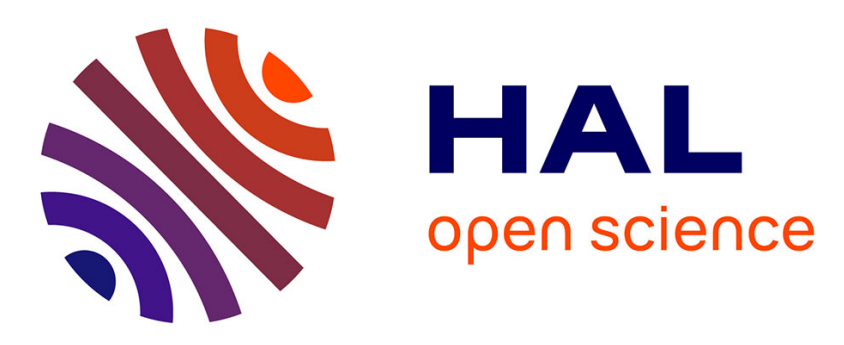

\title{
Identification of sheet metal hardening for large strains with an in-plane biaxial tensile test and a dedicated cross specimen
}

Wei Liu, Dominique Guines, Lionel Leotoing, Eric Ragneau

\section{To cite this version:}

Wei Liu, Dominique Guines, Lionel Leotoing, Eric Ragneau. Identification of sheet metal hardening for large strains with an in-plane biaxial tensile test and a dedicated cross specimen. International Journal of Mechanical Sciences, 2015, 101-102, pp.387-398. 10.1016/j.ijmecsci.2015.08.022 . hal-01203625

\section{HAL Id: hal-01203625 \\ https://hal.science/hal-01203625}

Submitted on 23 Sep 2015

HAL is a multi-disciplinary open access archive for the deposit and dissemination of scientific research documents, whether they are published or not. The documents may come from teaching and research institutions in France or abroad, or from public or private research centers.
L'archive ouverte pluridisciplinaire HAL, est destinée au dépôt et à la diffusion de documents scientifiques de niveau recherche, publiés ou non, émanant des établissements d'enseignement et de recherche français ou étrangers, des laboratoires publics ou privés. 


\title{
Identification of sheet metal hardening for large strains with an in-plane biaxial tensile test and a dedicated cross specimen
}

\author{
Wei LIU, Dominique GUINES*, Lionel LEOTOING, Eric RAGNEAU
}

Université Européenne de Bretagne, INSA-LGCGM-EA 3913, 20 Av. des Buttes de Coësmes, CS 70839, 35708 Rennes Cedex 7, France

\begin{abstract}
In this work, an in-plane biaxial tensile test of cruciform specimen is performed to identify the hardening behaviour of metallic sheets under large strains. Firstly, an optimal shape of the specimen is suggested. Then, a biaxial tensile test is carried out for an aluminium alloy AA5086. Experimental forces on the two axes of the specimen are measured during the test and strains in the central area of the specimen are post-treated by means of Digital Image Correlation (DIC) technique. Finally, by considering different yield criteria, the associated hardening laws are identified thanks to an inverse procedure based on a Finite Element (FE) modeling of the biaxial tensile test and on the experimental data mentioned above. The identified biaxial flow curves are then compared with the ones from the classical uniaxial tensile test.
\end{abstract}

Keywords: biaxial tensile test, cruciform specimen, hardening law, sheet metal forming, anisotropic yield criterion.

\section{Introduction}

Sheet metal forming processes are widely adopted in industries to produce thin-wall parts. Nowadays, with increasing demands for safety, lower weight or reduced fabrication costs, new materials and innovative forming processes emerge. In order to reduce the amount of the time-consuming and expensive trial-and-error processes, Finite Element (FE) simulations are intensively used to analyze the capabilities of sheet metal forming processes. To improve the accuracy of FE models, the material must be characterized for conditions close to the ones encountered in practice [1]. In sheet metal forming processes, the material is deformed under

*Corresponding author, Tel.: 33223238444

E-mail address: dominique.guines@insa-rennes.fr (D. Guines) 


\section{ACCEPTED MANUSCRIPT}

multi-axial states and is subjected to large strains. Hence, the identification of material constants, corresponding to the different behaviour models (yield criterion, plastic hardening ...), under biaxial tensile state has become a basic issue for the characterization of phenomenological models.

Characterization of material behaviour under biaxial tensile states can be performed by different tests such as: (i) hydraulic bulge tests of circular specimen [2], (ii) tension-internal pressure tests of tubular specimen [3], through-thickness compression tests using stacked specimens $[4,5]$ or (iii) biaxial tensile tests of flat cruciform specimen. Considering the inplane biaxial tensile test, a cruciform specimen is directly loaded along two perpendicular directions. This test presents several interests for the characterisation of material behaviours: first, it is a frictionless test without any contact between the tested specimen and tools; moreover, many strain paths ranging from uniaxial tension to biaxial tension can be encountered in the same test in different regions of the specimen; finally, by changing the displacement ratio between the two perpendicular axes, different linear or non linear biaxial strain and stress states can be obtained in the central region of the specimen. The main drawback of this test is related to the design of the cross specimen. Very recently, the international standard ISO16842 [6] has been proposed. This standard specifies the testing method for measuring the biaxial stress-strain curves of sheet metals subject to biaxial tension at an arbitrary stress ratio. The test piece is made of a flat sheet metal and has a uniform thickness. The measured biaxial stress-strain curves are used to determine contours of plastic work of the sheet samples. This standard is based on the research work of Kuwabara et al. [7] and considers that stresses are calculated analytically by assuming an equivalent cross section. This shape cannot be used for hardening identification since the strain level measured in the central zone is very low when necking appears in the arms. For low strains, many studies have been performed to determine the initial yield surface and estimate yield criterion parameters. Muller et al. [8] have presented an optimized geometry of cross tensile specimen with notches at corners to obtain a large zone of homogeneous deformation in the central area of the specimen. The beginning of plastic deformation is determined by the heat dissipation due to the plastic deformation. Naka et al. [9] have proposed a specimen with notches at the corners and two slits in the arms to make stresses and strains as homogeneous as possible in the central gage section. Effects of strain rate, temperature and sheet thickness on the yield locus of AZ31 magnesium alloy sheet were investigated. Merklein et al. [10], always on magnesium alloy AZ31, have designed a cruciform shape with six slits of various lengths in 


\section{ACCEPTED MANUSCRIPT}

each arm to determine initial and subsequent yield loci. Once again, the yield stresses are calculated by the measured forces and corresponding cross-sections. Strain fields are calculated by Digital Image Correlation (DIC) technique.

More recently, the development of optical full-field measurement techniques for analysing heterogeneous strain fields, such as DIC technique, has led to the development of new methodologies for characterising the plastic behaviour of materials [11]. The most common approach is based on inverse analysis methodologies, which consist in the calibration of the material model by the best set of material parameters that minimise the gap between predicted and experimental results. In this context, several works in literature have been proposed. Teaca et al. [12] have suggested two types of specimen shapes which can generate heterogeneous strain fields. The first shape with a hole in the central zone covered the stress range from uniaxial tension to that corresponding to plane strain and the second shape with four slots in each arm covered the stress range from uniaxial tension to equibiaxial tension. The strain was calculated by DIC technique and the inverse strategy of parameter identification, including the FE model of the specimen, is performed to determine some of the constants of the Ferron, Makkouk and Morreale (FMM) yield function. The other parameters were determined by means of the classical uniaxial tensile test. Zhang et al. [13] proposed a parameter identification process with a single biaxial tensile test for complex Bron and Besson anisotropic yield model for two metallic sheets (AA5086 and DP980). An identification stage based on the minimization of experimental and numerical principal strains along a specified path in the gauge area of the cruciform specimen was performed. Prates et al. [14] used a single equibiaxial tensile test of cruciform specimen to simultaneously identify the parameters of Hill 48 yield criterion and Swift isotropic hardening law by mixed numericalexperimental method. A cruciform shape, with tapered arms, was proposed. Nevertheless, this work was not experimentally validated. As seen in this literature review, the biaxial tensile test associated with cruciform specimen has been extensively used to determine the yield locus of sheet metal. Unfortunately, the equivalent strain level reached in these applications is usually very small, but sufficient for initial or subsequent yield locus identification.

Several attempts of cruciform shape design to reach large strains have also been presented. Green et al. [15] have proposed specimen geometry with a central section thinner than the rest of the specimen and seven parallel slots in each arm. The cruciform specimens were deformed up to effective strains of approximately $15 \%$ in biaxial stretching, along seven different linear 


\section{ACCEPTED MANUSCRIPT}

strain paths. An iterative procedure coupled with finite element analysis was performed to determine the various yield functions and biaxial flow curves. Tasan et al. [16] have demonstrated that a significant thickness reduction in the centre is necessary to reach fracture under a biaxial strain path. Abu-Farha et al. [17] have optimised two shapes of cruciform specimen to study micro-structural deformation mechanisms under biaxial strain state for lightweight materials at elevated temperature. The arms of the first geometry were tapered and a circular profile is used to define the thickness evolution. The other geometry has notches between arms and a circular flat-bottomed recess in the gauge area. However, in works presented above, only relatively low values of equivalent plastic strain (close to those obtained in uniaxial tension) are reached before plastic instabilities occur.

With the aim to determine forming limit strains of sheet metal, some studies have been led to define an appropriated cruciform shape with an onset of necking in the center of the specimen. Different strain paths must be tested to cover the whole forming limit curve (FLC), and in all cases, the rupture of the specimen must occur at the central point. Considering these requirements, $\mathrm{Yu}$ et al. [18] have suggested a cruciform specimen with two thickness reductions in the central region to obtain strain limits and study the influence of complex loading paths by finite element simulations. But this work was not validated by experiments. Zidane et al. [19] have adopted a two-steps thickness reduction in the central zone. The first zone is a square one with a constant thickness and the second one is a circular zone with a progressive thickness reduction defined by a circular profil. With this specimen, the rupture is always observed at the central point where various strain paths can be obtained by different speed ratios on the two arms. The whole FLC of aluminium alloy AA5086 has been determined. For the same specimen, Leotoing et al. [20] have numerically investigated the influence of both the yield criteria and hardening laws on the prediction of FLC. The main drawbacks of the proposed specimen shape are the complex geometry of the central area and the initial thickness of $4 \mathrm{~mm}$ required for the two thickness reductions.

In this work, in order to show the potential of the in-plane biaxial tensile test to capture the hardening behaviour of sheet metal for large strains, different shapes of cruciform specimen are numerically investigated. Based on FE results, a shape with thickness reduction at the central zone, slits along the arms and notches between two arms is proposed from a parametric study. The designed shape of cruciform specimen is validated by quasi-static equibiaxial tensile tests performed on an aluminium alloy AA5086. The strain in the central 


\section{ACCEPTED MANUSCRIPT}

area of the specimen is calculated by DIC method. Then, experimental data, corresponding to forces along the two arms and strains in the central part are used to determine the biaxial flow stress curve of the material for large equivalent strain (up to 30\%). The parameter identification is based on the FE model of the in-plane biaxial tensile test and on the minimization of the difference between experimental and calculated principal strains. In this identification stage, three yield criteria are evaluated (Mises, Hill48 and Bron and Besson). Results obtained from the biaxial tensile test are finally compared with those from uniaxial tensile test.

\section{Shape design of cruciform specimen}

As shown in bibliography overview, there is no standardized in-plane cross specimen which exhibits large strains in equibiaxial strain state. Very few researches about characterization of plastic behaviour of metallic sheets by biaxial tests on cruciform specimen under large strains have been reported. In order to obtain rupture (and consequently large strains) under different stress states and not only under the classical uniaxial tension, some cruciform specimen shapes, more or less complex, have been investigated. Very few of them have been validated by experiments, except the shape proposed by Zidane et al. [19], which is based on a two-step thickness reduction (from as received thickness $4 \mathrm{~mm}$ to final thickness $0.75 \mathrm{~mm}$ ). Nevertheless, the use of this shape for any sheet thickness seems difficult, particularly for sheets with small initial thicknesses. Another limitation of the cruciform shape with a progressive central thickness reduction defined by a curved profile is that large deformations are localized in the centre of the specimen leading to strongly heterogeneous strain fields on the specimen surface. For the inverse procedure of identification of material parameters, one possibility is to consider whole strain fields on the specimen surface during the test and to minimize the difference between numerical and experimental strain fields as previously performed by other authors [21]. In this study, the identification procedure aims to be simple and for this purpose just the strain evolution in the specimen central point during the test is analysed. Consequently, it has been chosen to define a constant central thickness zone where an almost homogeneous strain field is expected. To obtain robust values, the principal strains, used in the identification loop, are obtained by the average of strains calculated over some points located around the central point of the specimen, as shown hereafter. 


\section{ACCEPTED MANUSCRIPT}

To define a dedicated shape design which covers a large strain range, the in-plane equibiaxial tensile test is investigated by means of FE simulations carried out with the software ABAQUS. A $2 \mathrm{~mm}$ thickness sheet metal of aluminium alloy AA5086 is considered. The elastic parameters of this alloy are Young's modulus $E=73022 \mathrm{MPa}$ and Poisson's ratio $v=0.33$. In order to investigate the different shapes, an isotropic Mises yield criterion is first chosen and an isotropic hardening behaviour is assumed. This hardening behavior is introduced through the true stress-plastic strain law (Fig. 1) from uniaxial tensile test.

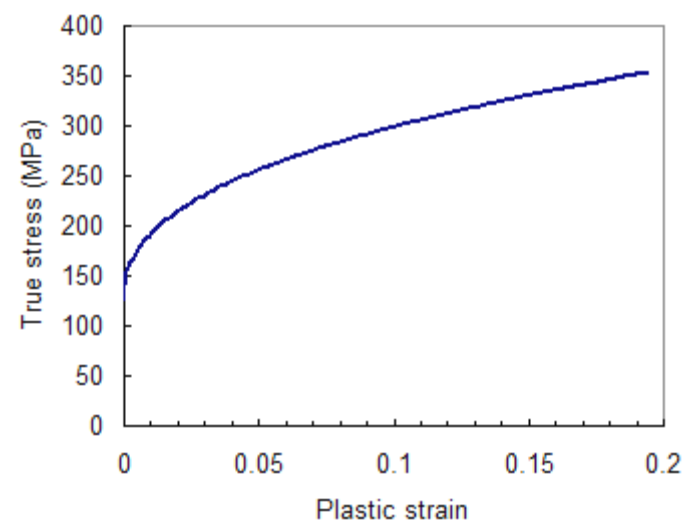

Fig. 1 True stress-plastic strain curve of AA5086

To evaluate the potential of different shapes, simulations are analysed for a value of $20 \%$ of the major principal strain $\varepsilon_{1}$. In a first step, the equibiaxial tensile test is simulated on the basic shape given Fig. 2a. The S3R shell elements are used in the FE model (Fig. 2b). Due to symmetries, only one quarter of the geometry is considered. The specimen can be divided into three zones: the central zone, the arms and the intersection of the arms. Fig. 3 shows the major principal strain $\varepsilon_{1}$, the equivalent plastic strain $\bar{\varepsilon}_{\mathrm{p}}$ and the strain state (ratio of in-plane principal strains $\varepsilon_{2} / \varepsilon_{1}$ ) for the basic specimen shape. At the same time, the value of $20 \%$ is reached for both the major principal strain and the equivalent plastic strain at the intersection between two consecutive arms (Fig. 3a and 3b), which corresponds approximately to a uniaxial tensile state in this area $\left(\varepsilon_{2} / \varepsilon_{1}=-0.5\right)$. The equivalent plastic strain in the central zone is very low (below 2\%, as shown in Fig. 3b) and strain state corresponds to an equibiaxial one $\left(\varepsilon_{2} / \varepsilon_{1}=1\right.$, Fig. 3c). Strain localisation at corners and onset of necking in arms limit the strains in the specimen central zone. 


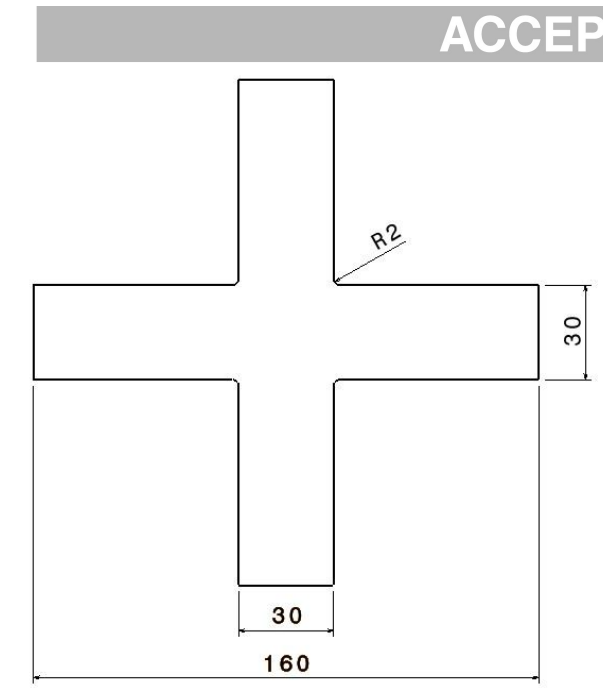

(a) Dimensions in $\mathrm{mm}$

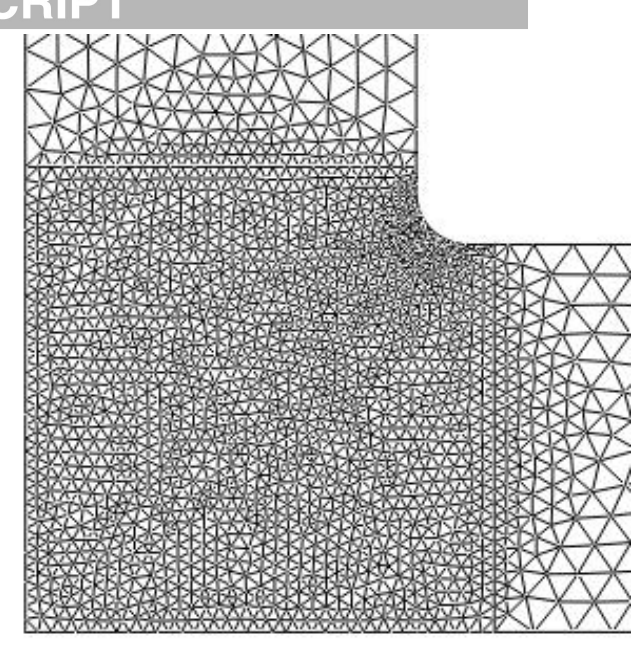

(b) Mesh with shell elements

Fig. 2 Basic specimen shape
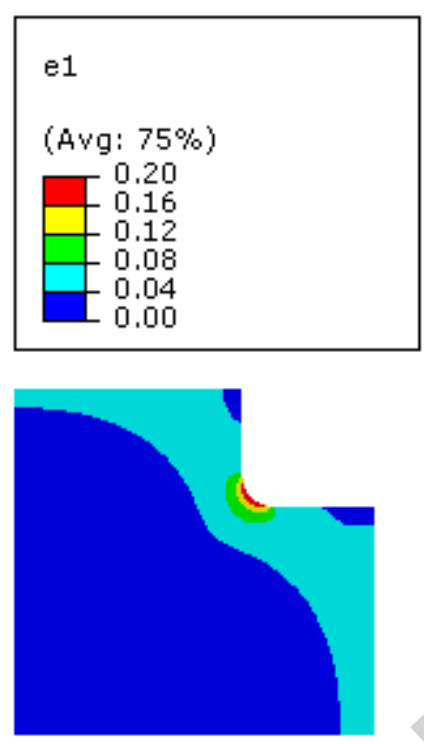

(a)

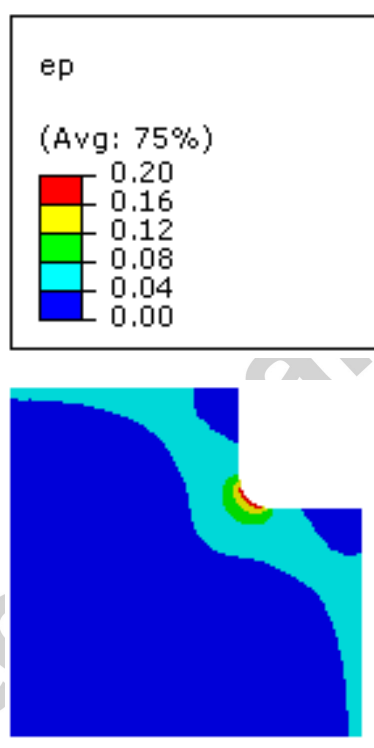

(b)
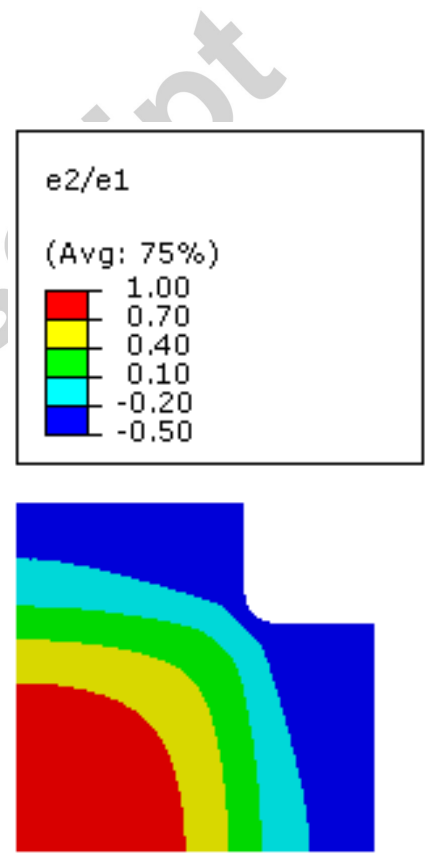

(c)

Fig. 3 Major principal strain, equivalent plastic strain and strain state for the basic specimen shape

As shown in literature, strain localisation at corners can be reduced or delayed by notches or radius. Moreover, to concentrate strains in the central zone, a thickness reduction of this zone is needed. The shape of this thickness-reduced zone is usually square or circular and a constant or variable thickness can be used. Then, a second shape with a flat circular thickness reduction and notches has been evaluated from FE simulations. A constant thickness-reduced zone is chosen to obtain stress and strain fields as homogeneous as possible in the central zone of the specimen. Preliminary simulations have shown that notches are more efficient 


\section{ACCEPTED MANUSCRIPT}

than radii, so notches have been preferred in this study (Fig. 4a). The thickness reduction is realized only on one side of the sheet and not in a symmetrical way to simplify the specimen manufacturing. Linear tetrahedral elements of type C3D4 are used to mesh the specimen (Fig. 4b). Potential of this shape is illustrated by simulation results given in Fig. 5 where the thickness $e$ and the radius $r$ of the thickness-reduced zone are respectively equal to $0.5 \mathrm{~mm}$ and $5 \mathrm{~mm}$. Compared to the basic shape, this second shape exhibits larger major principal strain $\left(8 \% \leq \varepsilon_{1} \leq 12 \%\right)$ in the central thickness-reduced zone (Fig. 5a). In this zone, an equibiaxial strain state is observed (Fig. 5c) and an equivalent plastic strain of $20 \%$ is reached. It must be noticed that the maximum value of $\varepsilon_{1}$ is again first reached at the junction between two consecutive arms (i.e. in notches) despite of the proposed shape modifications. As shown in Fig. $5 \mathrm{c}$, in this zone a ratio $\varepsilon_{2} / \varepsilon_{1}$ ranging from -0.2 to -0.5 is observed, typical of a stress state close to the uniaxial tension. The comparison between Fig. 3a and 5a shows that shape modifications have transferred the deformation of the specimen from arms, where the major principal strain is now less than $4 \%$, to the central zone.

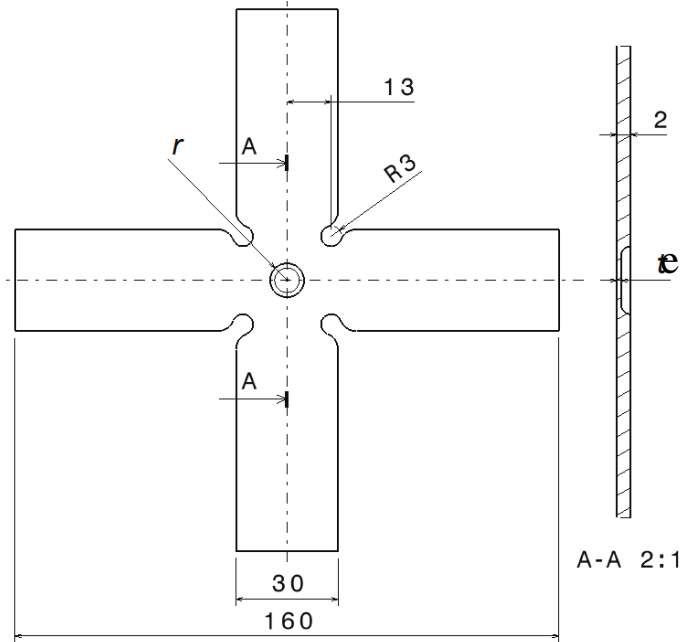

(a) Dimensions in $\mathrm{mm}$

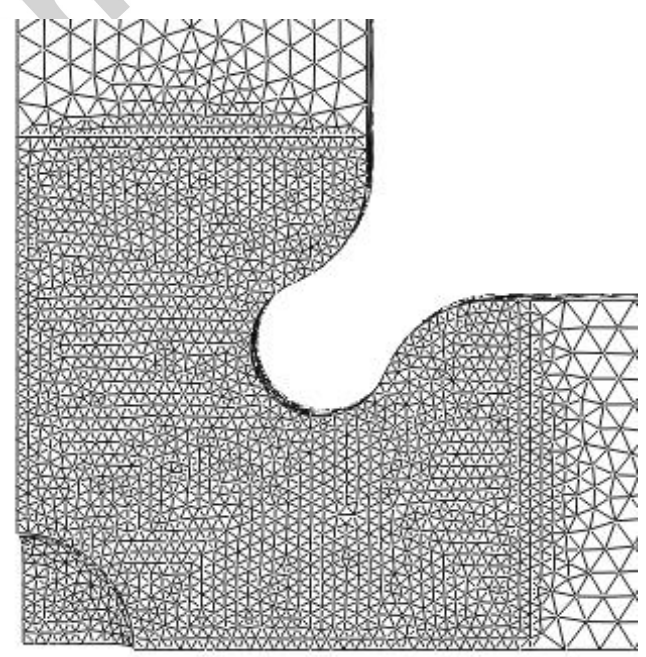

(b) 3D Mesh

Fig. 4 Specimen shape with thickness reduction and notches 

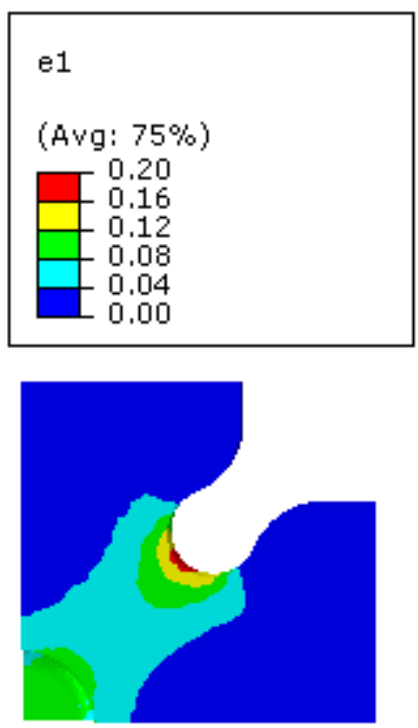

(a)
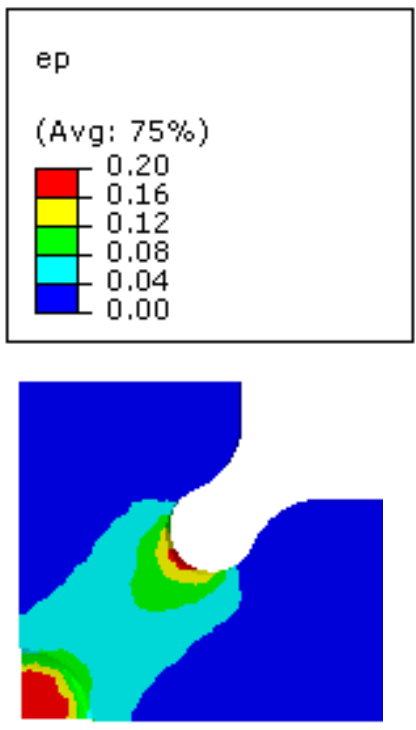

(b)
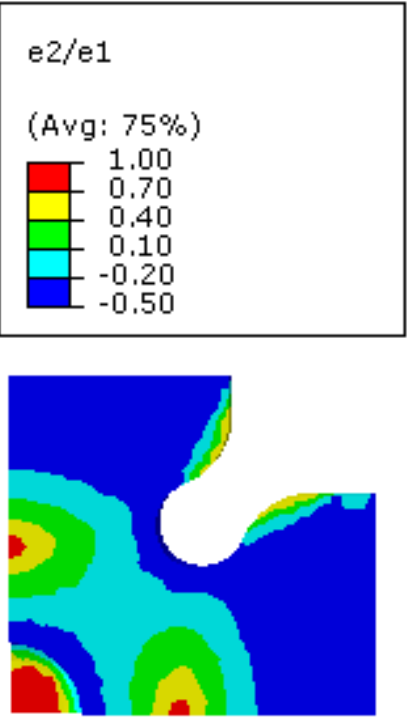

(c)

Fig. 5 Major principal strain, equivalent plastic strain and strain state for specimen shape with thickness reduction and notches

Since larger levels of deformation are required in the central zone, strain localization in notches must be reduced. As seen in literature, longitudinal slots can be added on each arm to decrease their transversal stiffness. The number and the position of each slot have a great influence on the strain and stress fields in the central zone of the specimen and particularly on the strain localization in notches. The slot width has been fixed to $1 \mathrm{~mm}$ for manufacturing considerations. From FE results, four slots in each arm have been chosen.

So, on the basis of results presented above, a parametric study has been performed. Five parameters have been introduced: radius $r$ of the thickness-reduced zone, position $D$ and radius $R$ of the notches, and finally, positions $S_{1}$ and $S_{2}$ of the slots, as shown in the Fig. 6 . Concerning, the thickness of the reduced central zone (parameter $e$ in Fig. 6), the smaller the thickness is, the larger the strains will be. Nevertheless, to avoid early rupture in this zone due to defects induced by the machined process (milling or lathing), the thickness is limited to a value of $0.6 \mathrm{~mm}$. In previous works [28] on the same alloy, authors have shown that a machining operation does not change neither the macroscopic response of the material nor the local behaviour corresponding for example to the limit strains. The best set of parameters, i.e. leading to the larger strains in the thickness-reduced zone and minimizing the strain localization in notches and at slot ends, are given in Tab. 1. 

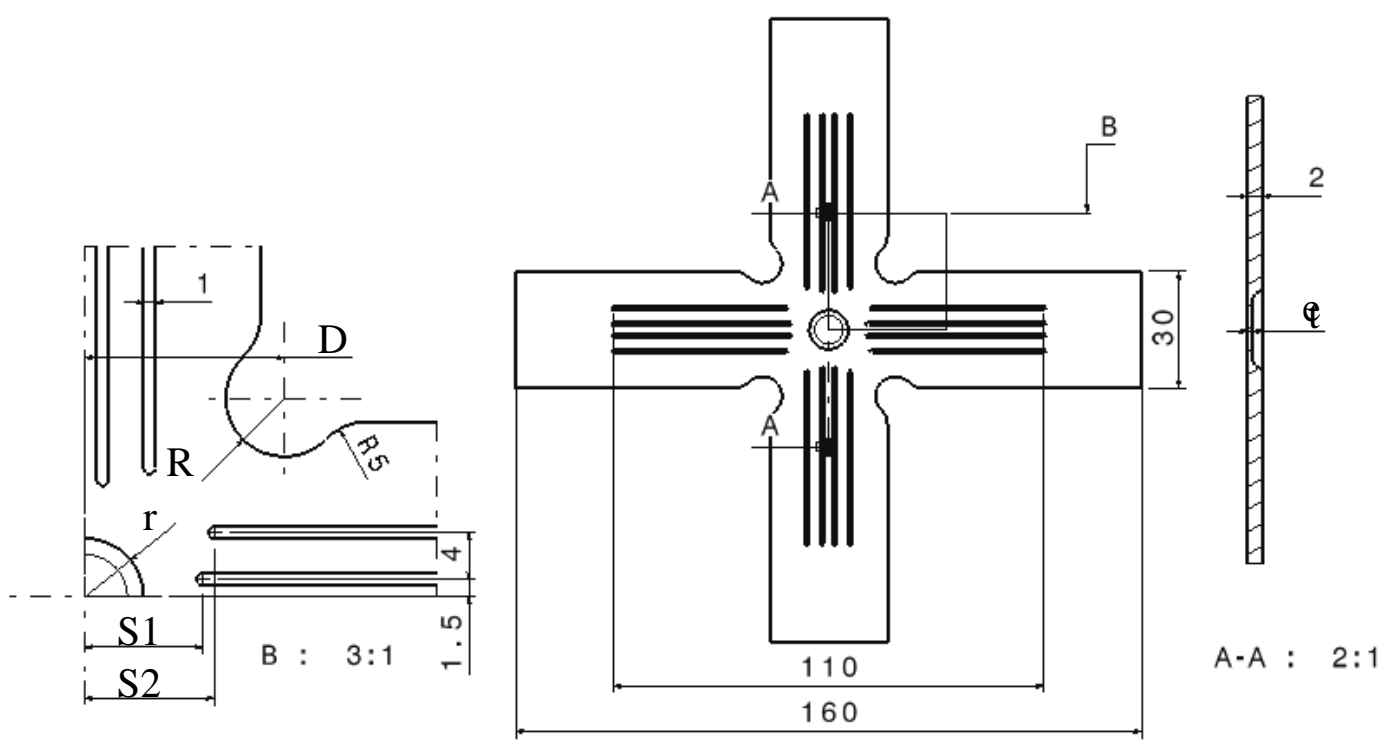

Fig. 6 Dimensions of optimized cruciform specimen (in $\mathrm{mm}$ )

Tab. 1 Dimension values (in $\mathrm{mm}$ ) of the central area

\begin{tabular}{ccccc}
\hline$r$ & $D$ & $R$ & $S 1$ & $S 2$ \\
\hline 5 & 17 & 5 & 10 & 11
\end{tabular}

The mesh of the FE model, discretized with linear tetrahedral C3D4 solid elements, is presented Fig. 7. The equivalent plastic strain at the central zone reaches $30 \%$ when the major principal strain is about $20 \%$ near the ends of slots and in the fillet radius between the two different thickness zones (Fig. 8). The interest of slots is clearly shown since the maximum strain localization appears now in the thickness-reduced zone. The so-defined specimen shape presented in Fig. 6 with optimal dimensions (Tab. 1) will be used in the following to characterize the hardening behavior of an AA5086 aluminium alloy up to large equivalent plastic strain under equibiaxial tensile state. 


\section{ACCEPTED MANUSCRIPT}

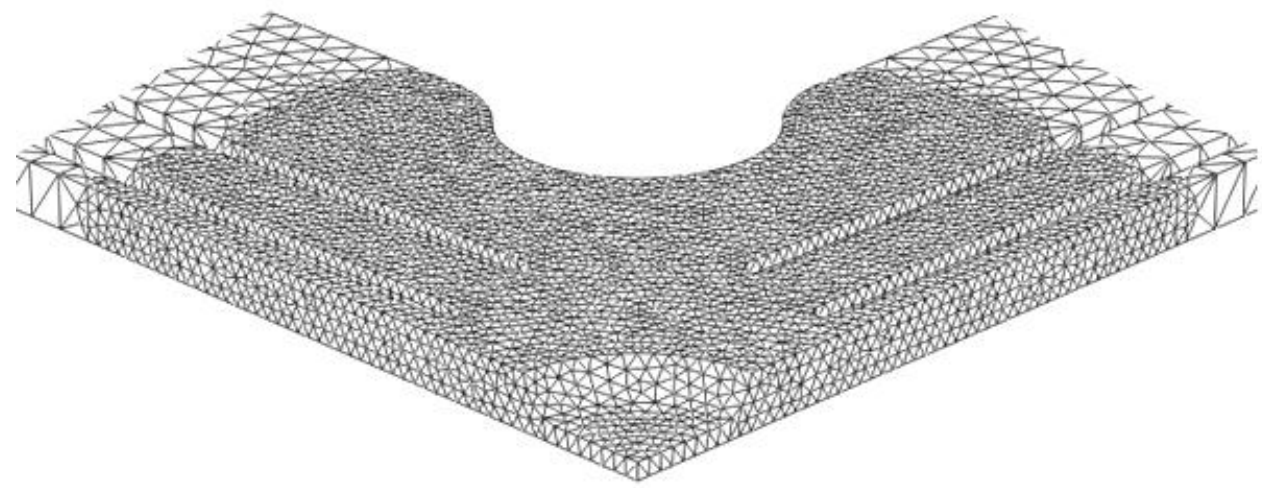

Fig. 7 3D mesh of the optimized cruciform specimen shape

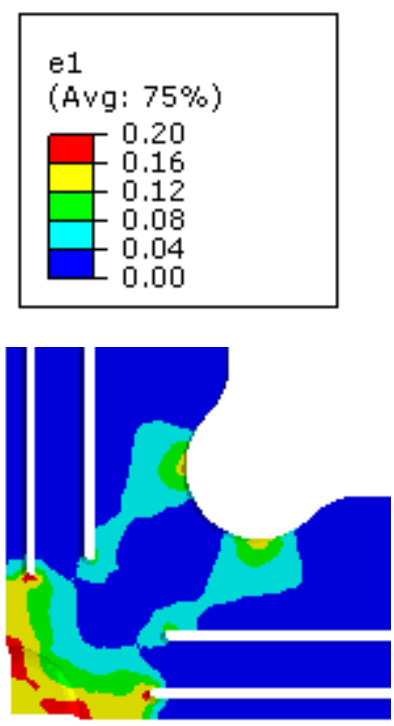

(a)
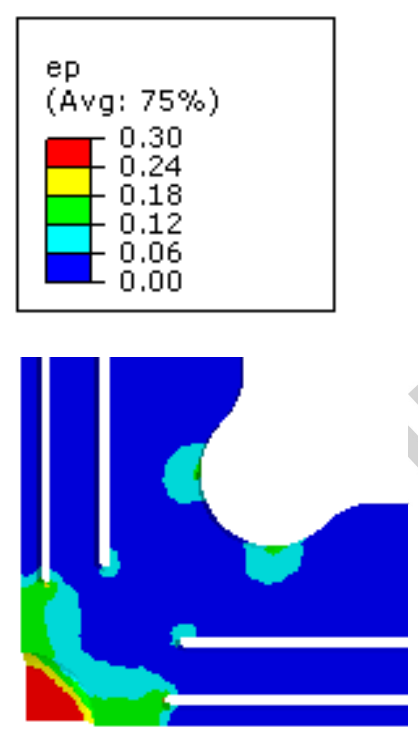

(b)
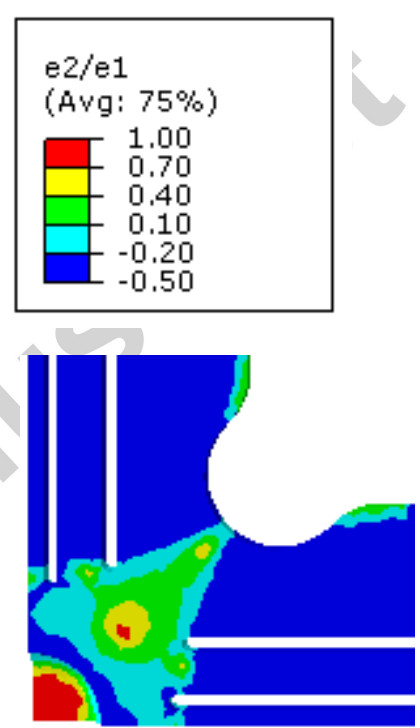

(c)

Fig. 8 Major principal strain, equivalent plastic strain and strain state for the optimized cruciform specimen shape

\section{Experimental validation}

A servo-hydraulic testing machine [19] with four independent dynamic actuators is used to carry out the biaxial tensile tests. For each actuator, the loading capacity is $50 \mathrm{kN}$ and the loading speed can reach up to $2 \mathrm{~m} / \mathrm{s}$. Two force sensors are used to measure the experimental forces along the two perpendicular axes. In this work, only quasi-static equibiaxial tensile tests at room temperature are performed. The imposed velocities are $1 \mathrm{~mm} / \mathrm{s}$ on each arm of the specimen. The $2 \mathrm{~mm}$ thick cruciform specimen of aluminium alloy AA5086 is presented Fig. 9a. 


\section{ACCEPTED MANUSCRIPT}

Before the test, a random speckle pattern is generated on the surface of the specimen (Fig. 9b). During the test, the central area of the cruciform specimen is filmed. The image resolution is 1024 pixels $\times 1024$ pixels and the acquisition rate is 250 frames/s. The size of the filmed zone is $30 \mathrm{~mm} \times 30 \mathrm{~mm}$. The crack initially occurs in the central zone of the specimen, along the transverse direction. The strain fields at the top surface of the specimen are calculated by DIC technique with the software CORRELA [22].

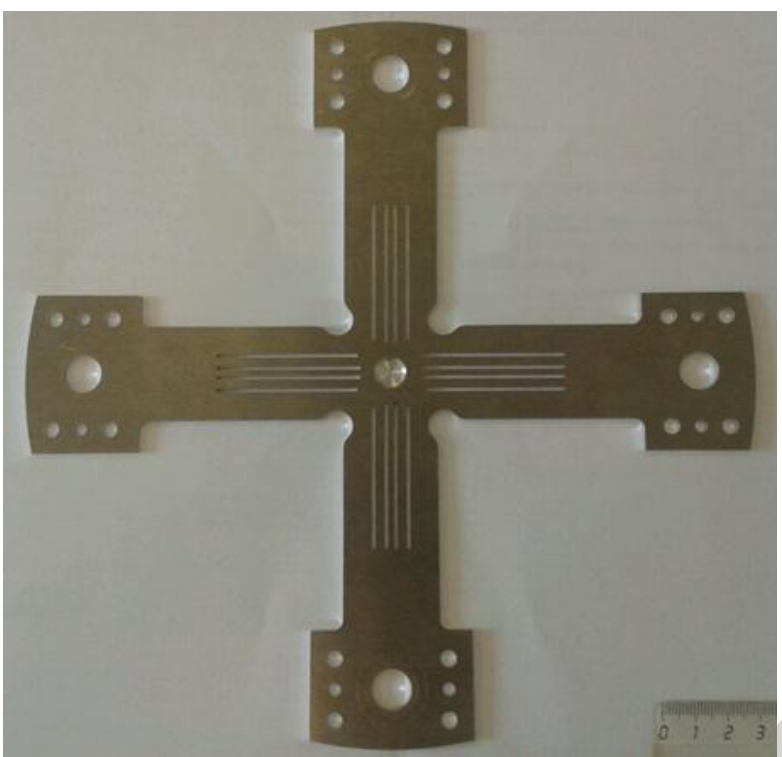

(a) Cruciform specimen geometry

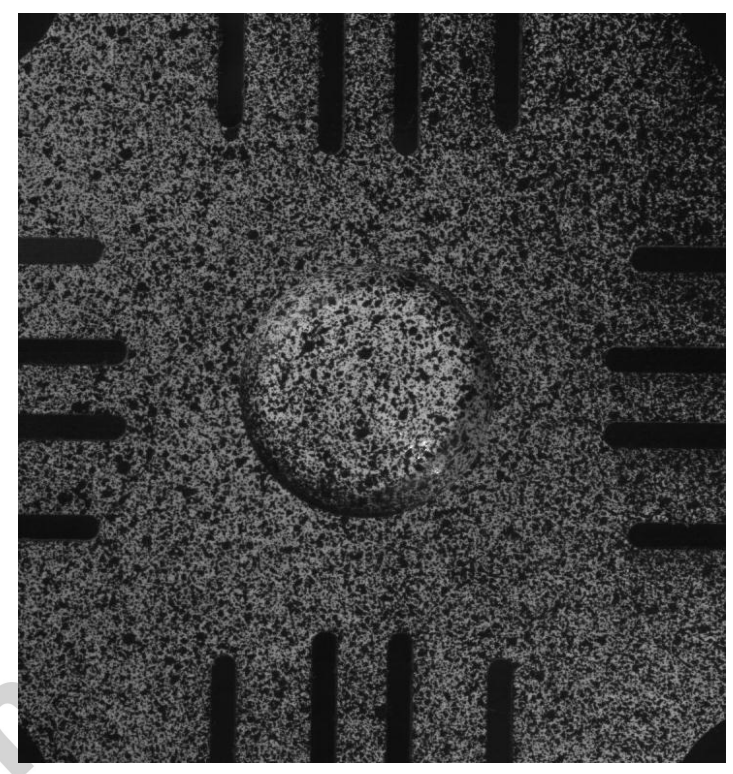

(b) Speckle of central zone

Fig. 9 Cruciform specimen machined from aluminium alloy AA5086 sheets of $2 \mathrm{~mm}$ thick

An area around the central thickness reduction zone is discretised by subsets and treated by DIC (Fig. 10). The size and distance of square subsets are respectively 32 pixels $\times 32$ pixels and 16 pixels $\times 16$ pixels which leads to 14 strain calculation points along each direction $(\mathrm{X}$ and $\mathrm{Y})$. Considering the image resolution and the dimensions of the filmed zone, a resolution of 0.037 $\mathrm{mm} /$ pixel is obtained. The displacement vectors of the gauge zone are shown in Fig. 11, it can be seen that the position of the central point is nearly kept fixed. Details on strain calculations are given in [13].

The equivalent strain, major and minor principal strain fields in the central zone of specimen at the time $t=1.54 \mathrm{~s}$ are shown in Fig. 12, Fig. 13 and Fig. 14 respectively. As expected, the equivalent strain reaches $30 \%$ just before the crack of specimen $(\mathrm{t}=1.612 \mathrm{~s})$, whereas the principal strains are about $16 \%$ for the major strain and $14 \%$ for the minor strain. The 


\section{ACCEPTED MANUSCRIPT}

maximum deformation appears in the fillet between the flat central zone and the non-reduced thickness zone on the central axis of the specimen (transverse direction).

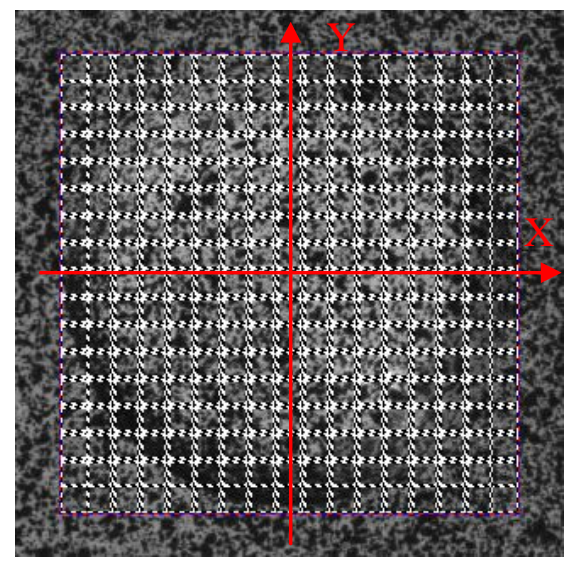

Fig. 10 Gauge zone

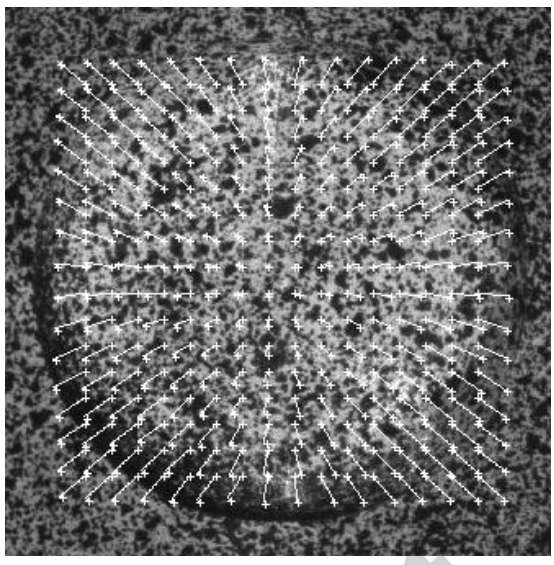

Fig. 11 Displacement vectors

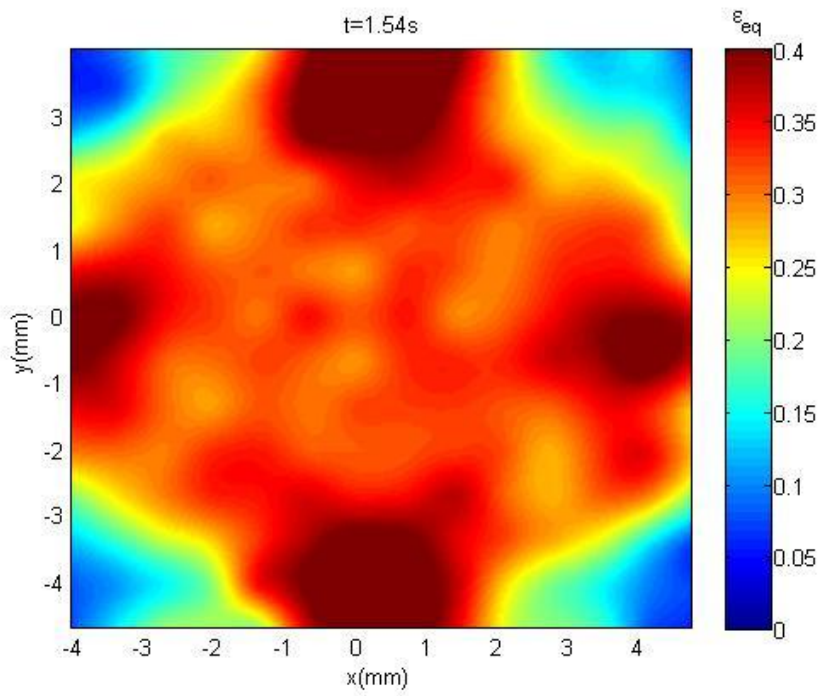

Fig. 12 Equivalent strain field before crack 


\section{ACCEPTED MANUSCRIPT}

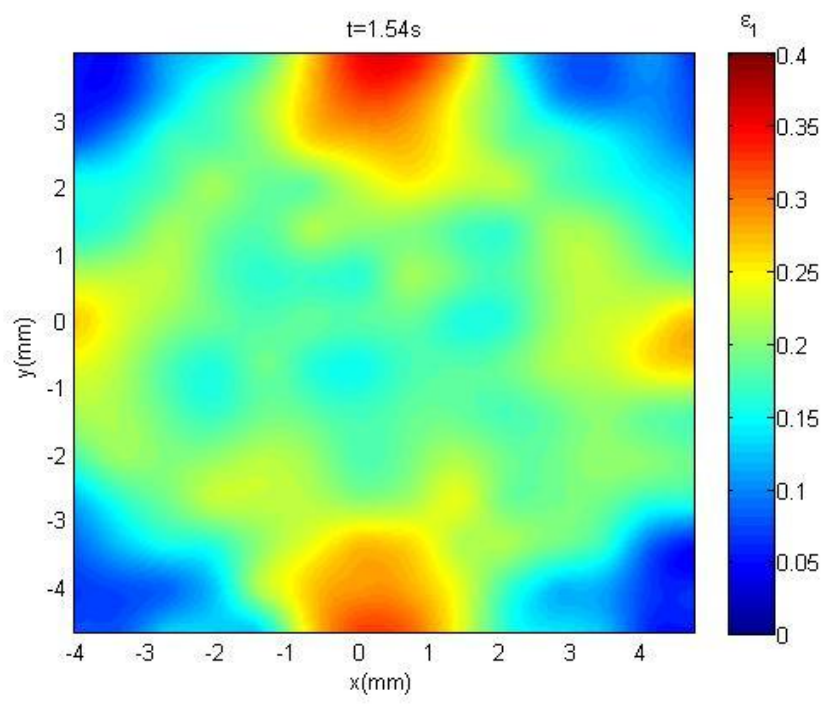

Fig. 13 Major principal strain field before crack

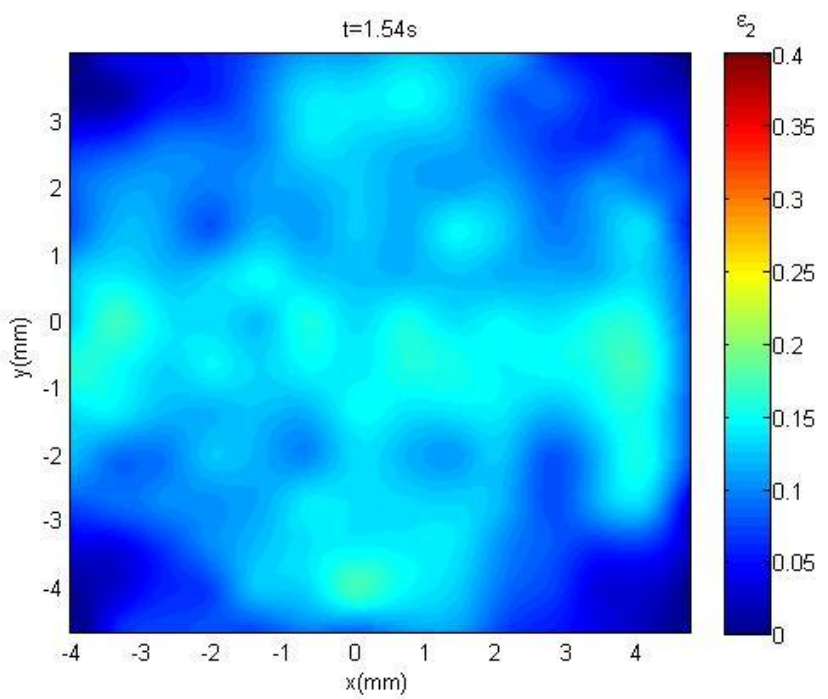

Fig. 14 Minor principal strain field before crack

The experimental curves of principal strains at the central point of the specimen are shown by Fig. 15. To get robust values of principal strains near the central point $(x=y=0 \mathrm{~mm})$ of the specimen, the principal strains are averaged as follows:

$$
\varepsilon(t)=\frac{1}{m \times n} \sum_{i=1}^{m} \sum_{j=1}^{n} \varepsilon(i, j, t)
$$

where $m$ and $n$ are the numbers of points to be averaged in each direction and $t$ is the time. Here, the average strains are calculated for $m=n=3$, corresponding to a square area 


\section{ACCEPTED MANUSCRIPT}

$(1.2 \times 1.2 \mathrm{~mm})$. The strain versus time curves are typical of Portevin-Le-Chatelier (PLC) effects, with steps on the strain evolutions, especially between $t=0.6 \mathrm{~s}$ and $t=1.2 \mathrm{~s}$. This phenomenon is well known for 5000 series aluminium alloys [23] in simple shear and uniaxial tests.

Forces along the two arms of the cruciform specimen are shown in Fig. 15. Fx and Fy correspond respectively to the rolling and transverse directions. PLC effects have also an impact on the macroscopic response of the specimen, more particularly on the tensile forces which present small oscillations. Since the modelling of this phenomenon is not integrated in the FE element model of the biaxial tensile test, experimental forces Fx and Fy presented in Fig. 15, have been filtered in order to be applied as boundary conditions in the FE model. Due to small mechanical gaps introduced in connections of the different links used to clamp the four arms of the specimen at each actuator, a slight out of synchronization is observed between the two $\mathrm{X}$ and $\mathrm{Y}$ axes.

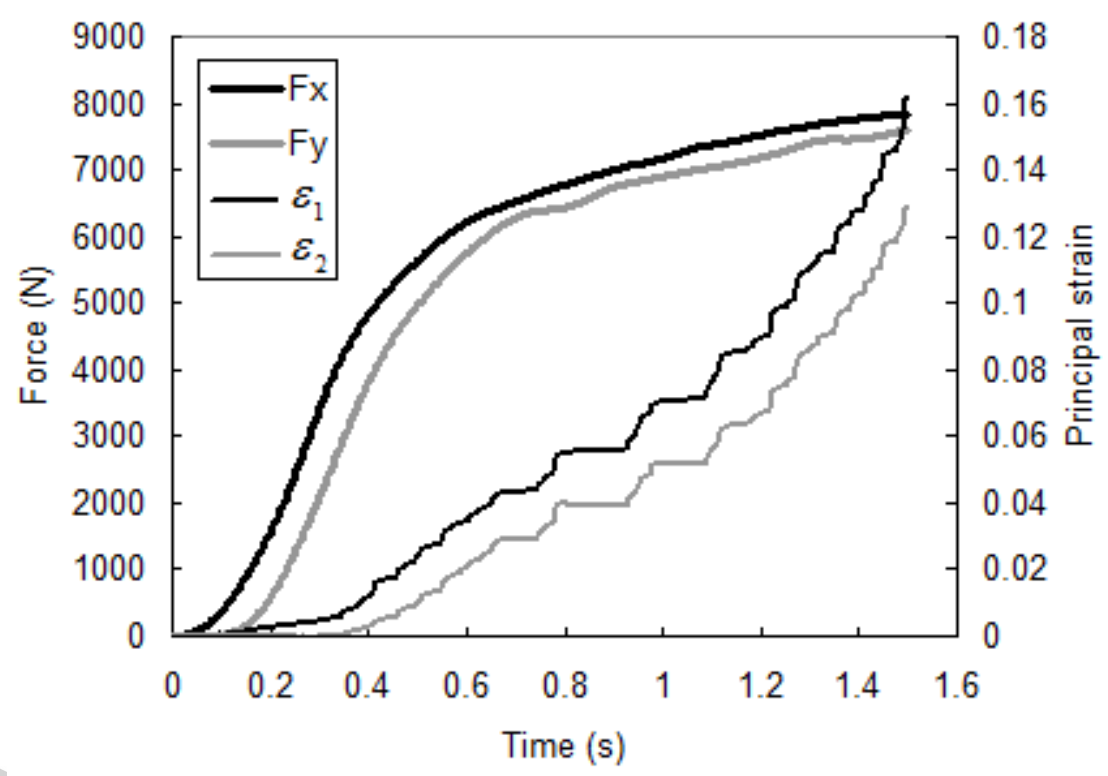

Fig. 15 Experimental principal strains and forces

For a velocity of $1 \mathrm{~mm} / \mathrm{s}$ imposed on each arm of the cross specimen, an equivalent strain rate of about $0.1 \mathrm{~s}^{-1}$ is reached at the beginning of the test in the central point of the specimen. This value grows progressively up to $1 \mathrm{~s}^{-1}$ at the end of the test. Due to PLC effects, the strain rate is very fluctuating during the test. 


\section{ACCEPTED MANUSCRIPT}

\section{Parameter identification of hardening behaviour}

\subsection{Inverse analysis procedure}

The cross section of the central zone of the specimen is not constant and stress and strain fields are not homogeneous. Then, stress or strain cannot be calculated in an analytical way. Hence, inverse analysis is adopted to identify the material constants of the hardening law, as shown in Fig. 16. The simulated principal strain curves at the centre of the FE model are compared with the experimental ones. To carry out the optimization process, the software platform ModeFRONTIER [24] is used and the Simplex algorithm is chosen. The optimization algorithm Simplex was preferred in the identification process. Like hill climbing algorithms, the Simplex method may not converge to the global minimum and can stop at local optima. To be sure that the global minimum was found, several optimizations were launched with various initial sets of parameters. The Simplex method presents the advantage of using $\mathrm{p}+1$ vectors (with $\mathrm{p}$ the number of parameters) and then facilitates the search of the global minimum in the p-dimensional space. The error function $Q$ between simulated and experimental strains is defined as follows:

$$
Q\left(\varepsilon_{1 \operatorname{sim}}, \varepsilon_{2 \operatorname{sim}}\right)=\left(\sqrt{\sum_{i}^{n}\left(\varepsilon_{1 \operatorname{sim}}^{i}-\varepsilon_{1 \exp }^{i}\right)^{2}} / \sqrt{\sum_{i}^{n}\left(\varepsilon_{1 \exp }^{i}\right)^{2}}+\sqrt{\sum_{i}^{n}\left(\varepsilon_{2 \operatorname{sim}}^{i}-\varepsilon_{2 \exp }^{i}\right)^{2}} / \sqrt{\sum_{i}^{n}\left(\varepsilon_{2 \exp }^{i}\right)^{2}}\right)[2]
$$

Here, $n$ is the total number of the time points of simulation; $\varepsilon_{1 \text { sim }}$ and $\varepsilon_{2 s i m}$ are the major and minor principal strains from FE model, calculated for the same area $(1.2 \times 1.2 \mathrm{~mm})$ than the experimental one ; $\varepsilon_{\operatorname{lexp}}$ and $\varepsilon_{2 \exp }$ are obtained by the Hermite interpolation of the 
experimental principal strain curves of the specimen at each simulation time point.

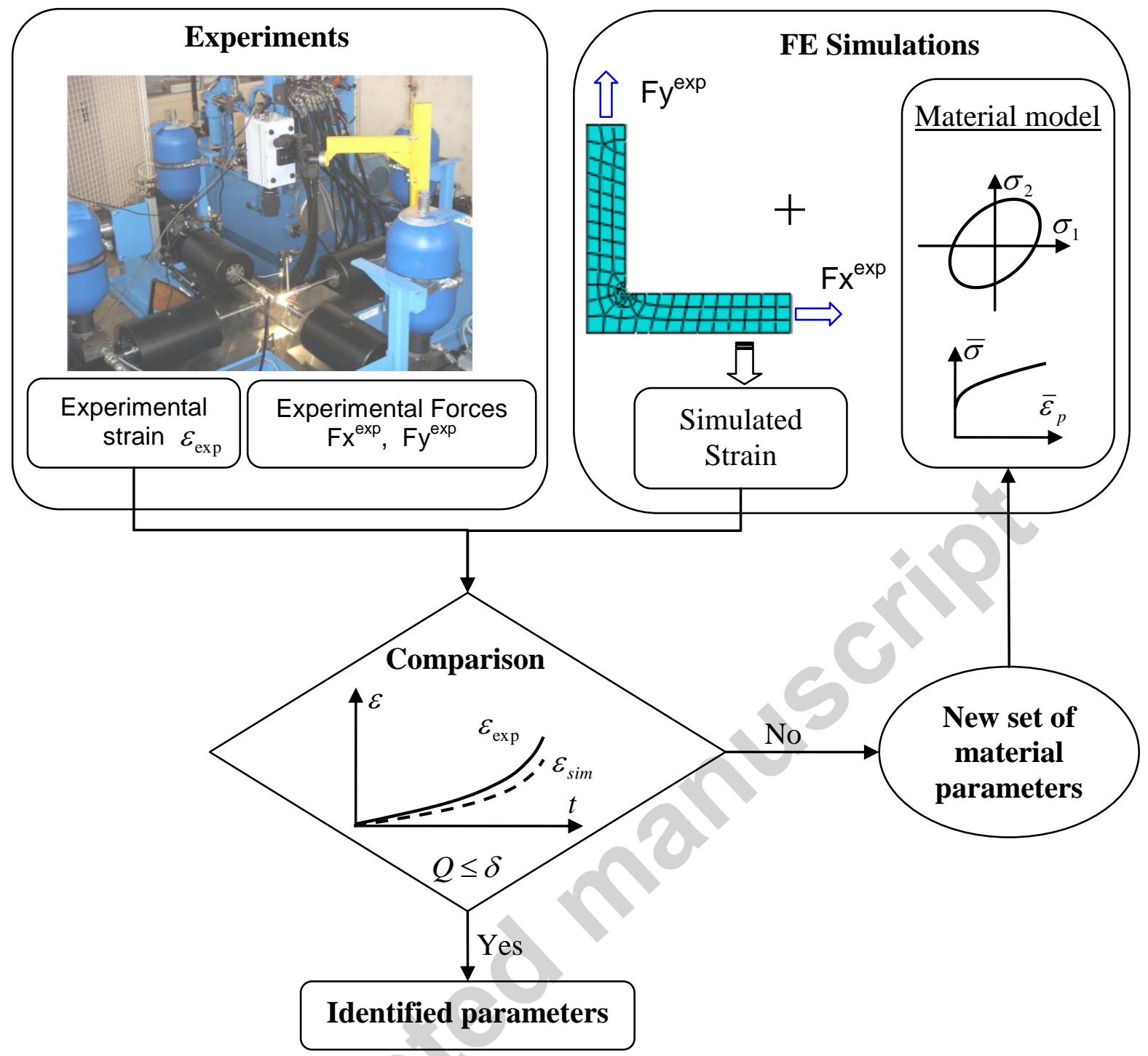

Fig.16 Flowchart of inverse procedure for hardening identification

\subsection{Finite element model of the in-plane biaxial tensile test}

Previously to the calibration stage, a FE model must be defined and the element size should be chosen small enough to capture the deformation localisation. Due to the symmetry, a quarter of the FE model of cruciform specimen is built. For the material model, anisotropic Hill48 yield criterion and a Voce hardening law both identified in a previous work by Zidane [28] have been used. The experimental forces $\mathrm{Fx}^{\mathrm{exp}}$ and $\mathrm{Fy}^{\mathrm{exp}}$ are applied to FE models, which include the slight out of synchronization observed between the two axes. Based on these assumptions, a parametric study with successive refined meshes has been led and appropriated 


\section{ACCEPTED MANUSCRIPT}

element sizes have been chosen (linear tetrahedral C3D4 element). A final element size of $0.1 \mathrm{~mm}$ in the central zone, notches and slit ends is adopted (Fig. 17a) and will be considered as a reference. Unfortunately, with this mesh, FE simulations are very time-consuming. So, to keep simulation times compatible with the inverse procedure which requires many simulations, a FE model with 2D linear shell element mesh is proposed. The shell model has been divided into three zones with different thicknesses: (i) the central flat thickness-reduced zone with $\mathrm{t}=0.625 \mathrm{~mm}$, (ii) a transition zone corresponding to the fillet radius with a thickness of $1.31 \mathrm{~mm}$ and (iii) the last zone with the $2 \mathrm{~mm}$ initial thickness. The thickness of the transition zone has been chosen as the average value of thicknesses of the central zone and the initial sheet. From successive simulations, adequate element sizes have been defined in these three zones of the specimen.

The equivalent plastic strain fields simulated by FE models with solid and shell elements are presented in Fig. 17. Distributions of the equivalent plastic strain are almost the same for the two models, although the localisation at the edge of central thickness-reduced zone in the solid model is more pronounced than in the shell model. The evolution of major and minor principal strain at the central zone has been also compared between the two models, as shown in Fig. 18. It confirms that the major and minor principal strain curves are very close for the two models. It can be concluded that the proposed shell mesh refinement is well adapted to precisely describe the behaviour of the cruciform specimen shape proposed in Fig. 6. The 3D element mesh with the appropriated element size in the central zone requires 814708 linear tetrahedral elements of type C3D4, leading to a computational time of 31096s (processor Intel $3.2 \mathrm{GHz}$ with 16 Go RAM). The same specimen, meshed with shell elements, requires 4660 S4R elements, leading to a computational time of 222 s, which corresponds to a ratio of 140 between the two computational times on the same computer. 


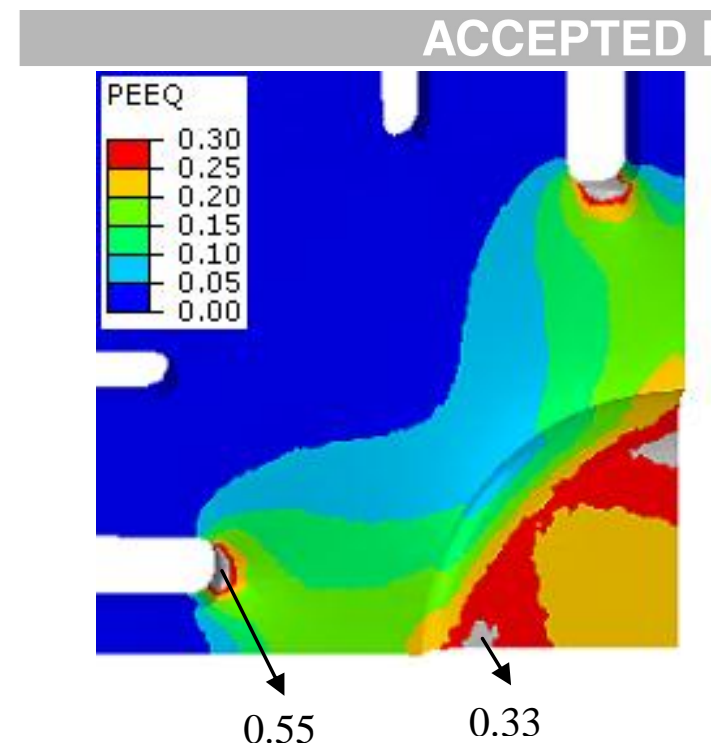

(a)

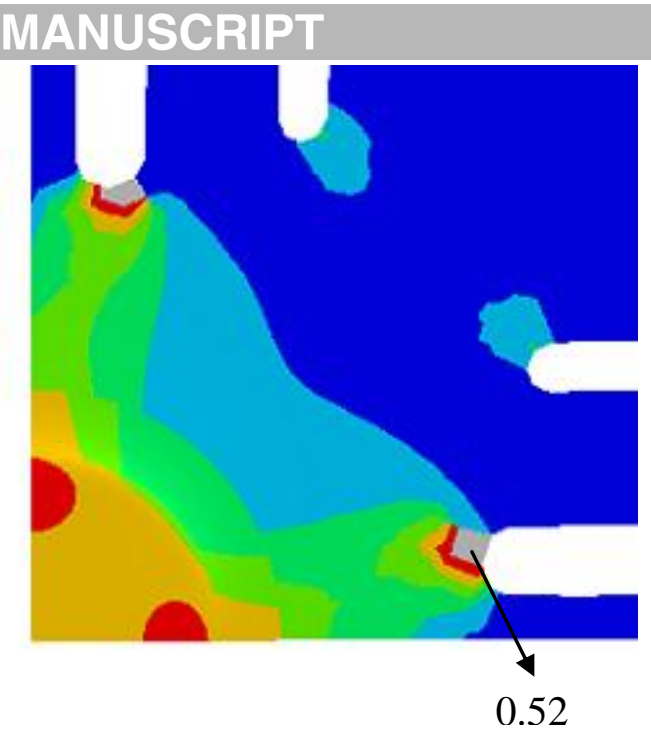

(b)

Fig. 17 Comparison of simulated equivalent plastic strain (PEEQ) fields from 3D solid element mesh (a) and 2D shell element mesh (b).
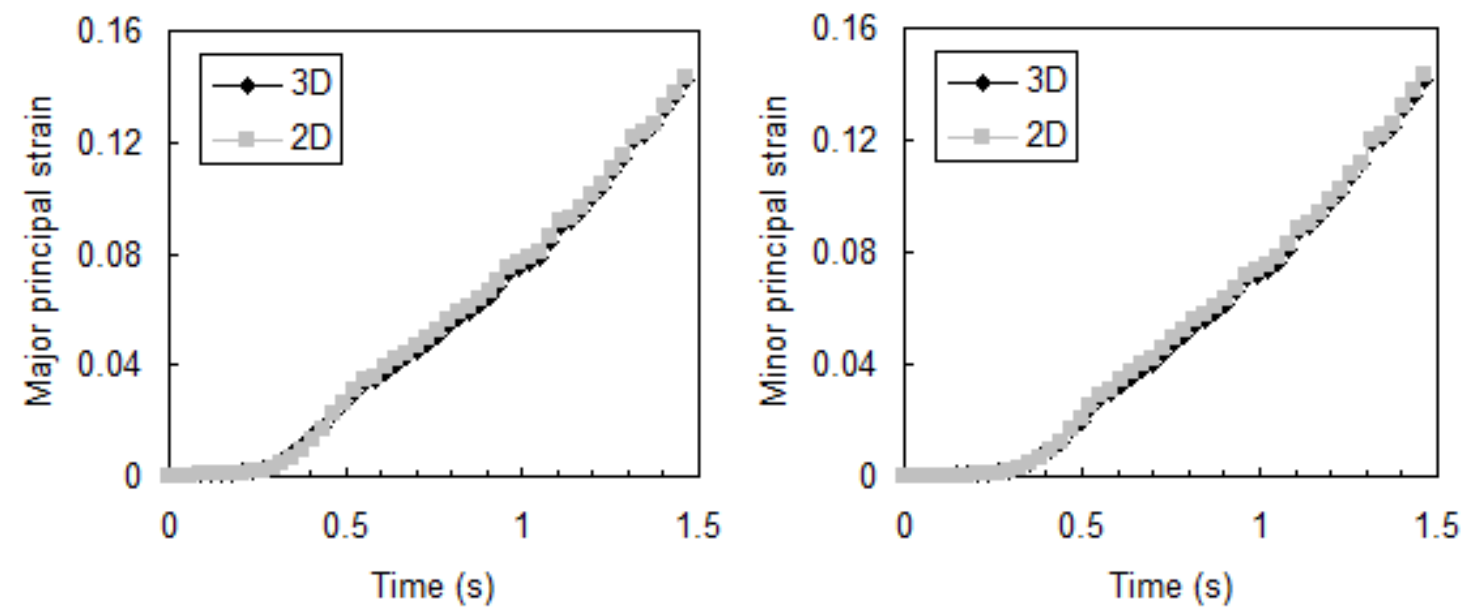

Fig. 18 Comparison of principal strain at central point for 3D and 2D mesh

\subsection{Material models}

To describe the material behaviour, an elasto-plastic model is adopted. The elasticity is described by Hooke's law with Young's modulus $E=73022 \mathrm{MPa}$, Poisson's ratio $v=0.33$. For the plastic behaviour, the associated flow rule is assumed and an isotropic hardening is introduced. Three yield criteria are considered, one isotropic and two anisotropic models. The first anisotropic one is the well-known Hill48 criterion and the second one is the advanced Bron and Besson (B\&B) criterion [25]. The first two plastic criteria are already introduced in 


\section{ACCEPTED MANUSCRIPT}

ABAQUS environment. For the Bron and Besson criterion, the user subroutine UMAT was used.

\subsubsection{Yield functions}

For the identification of hardening laws, three yield functions $\psi\left(\sigma_{i j}\right)$, written in function of stress tensor components, are defined as follows for plane stress conditions:

Von Mises:

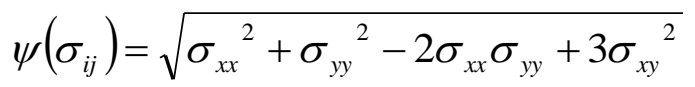

Hill48:

$$
\psi\left(\sigma_{i j}\right)=\sqrt{(G+H) \sigma_{x x}^{2}+(F+H) \sigma_{y y}^{2}-2 H \sigma_{x x} \sigma_{y y}+2 N \sigma_{x y}^{2}}
$$

The constants $F=0.632, G=0.671, H=0.329$ and $N=1.460$, with $\mathrm{G}+\mathrm{H}=1$ for plane stress conditions, are calculated from the three plastic anisotropic coefficients $r_{0}=0.49, r_{45}=0.62$ and $r_{90}=0.52$, determined in uniaxial tension by the ratio of width plastic strain rate to normal plastic strain rate for the three directions $\left(0^{\circ}, 45^{\circ}\right.$ and $\left.90^{\circ}\right)$ from the rolling one [26].

The parameters of the advanced phenomenological Bron and Besson yield function for AA5086 have been identified from a single biaxial test in a previous work [26]. This yield function is based on:

$$
\begin{gathered}
\psi\left(\sigma_{i j}\right)=\left(\sum_{k=1}^{K} \alpha^{k}\left(\bar{\sigma}^{k}\right)^{a}\right)^{1 / a} \\
\text { with } \bar{\sigma}^{k}=\left(\psi^{k}\right)^{1 / b^{k}} \\
\psi^{1}=\frac{1}{2}\left(\left|S_{2}^{1}-S_{3}^{1}\right|^{b^{1}}+\left|S_{3}^{1}-S_{1}^{1}\right|^{b^{1}}+\left|S_{1}^{1}-S_{2}^{1}\right|^{b^{1}}\right)
\end{gathered}
$$




$$
\begin{gathered}
\psi^{2}=\frac{3^{b^{2}}}{2^{b^{2}}+2}\left(\left|S_{1}^{2}\right|^{b^{2}}+\left|S_{2}^{2}\right|^{b^{2}}+\left|S_{3}^{2}\right|^{b^{2}}\right) \\
s^{k}=L^{k}: \sigma \\
L^{k}=\left(\begin{array}{cccccc}
\left(c_{2}^{k}+c_{3}^{k}\right) / 3 & -c_{3}^{k} / 3 & -c_{2}^{k} / 3 & 0 & 0 & 0 \\
-c_{3}^{k} / 3 & \left(c_{1}^{k}+c_{2}^{k}\right) / 3 & -c_{1}^{k} / 3 & 0 & 0 & 0 \\
-c_{2}^{k} / 3 & -c_{1}^{k} / 3 & \left(c_{1}^{k}+c_{2}^{k}\right) / 3 & 0 & 0 & 0 \\
0 & 0 & 0 & c_{4}^{k} & 0 & 0 \\
0 & 0 & 0 & 0 & c_{5}^{k} & 0 \\
0 & 0 & 0 & 0 & 0 & c_{6}^{k}
\end{array}\right)
\end{gathered}
$$

Where: $\alpha^{1}=0.72, \alpha^{2}=1-\alpha^{1}=0.28, a=0.16, b_{1}=13, b_{2}=8.41, c_{1}^{1}=1.06, c_{2}^{1}=1.1$, $c_{3}^{1}=0.82, c_{4}^{1}=0.95, c_{5}^{1}=c_{6}^{1}=1, c_{1}^{2}=0.75, c_{2}^{2}=0.47, c_{3}^{2}=0.78, c_{4}^{2}=0.62, c_{5}^{2}=c_{6}^{2}=1$. The shapes of the three yield functions are shown in Fig. 19.

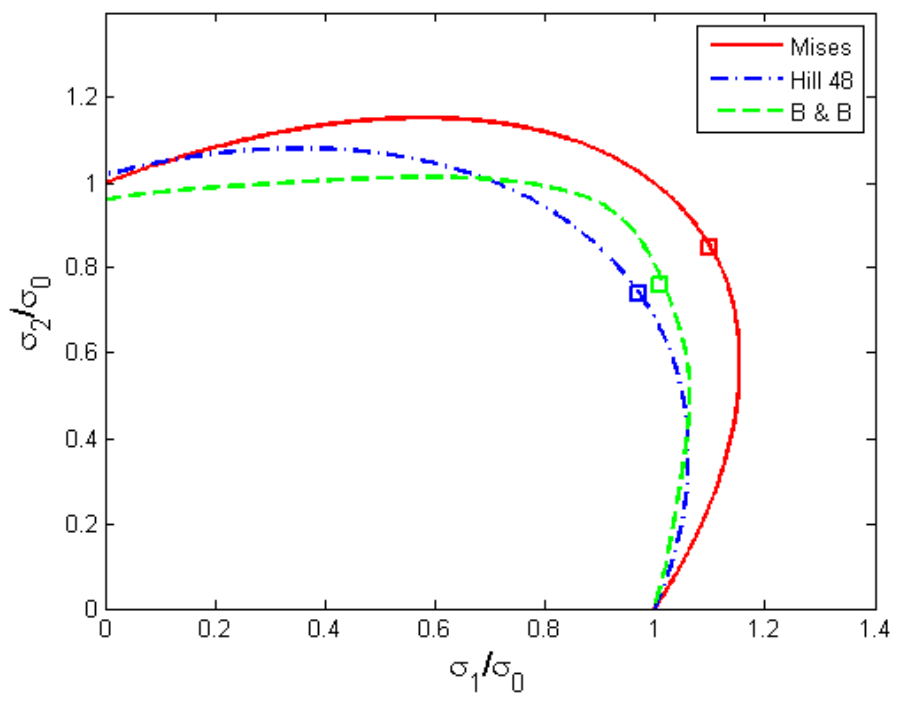

Fig. 19 Mises, Hill48 and Bron and Besson yield functions

\subsubsection{Hardening law}

A modified form of Voce's hardening has been adopted as follows [27] to limit the saturating behaviour of classical Voce's formulation:

$$
\bar{\sigma}=\sigma_{0}+K \sqrt{1-\exp \left(-n \bar{\varepsilon}_{p}\right)}
$$




\section{ACCEPTED MANUSCRIPT}

This hardening law has been identified (Tab. 2) with the three yield criteria (Mises, Hill48 and Bron and Besson), respectively.

Concerning the identification stage, a uniformly distributed design of experiment (DOE) with 150 samples, based on a Sobol sequence in modeFRONTIER, have been performed for each yield criteria and the cost function (Eq. 2) has been evaluated for each sample. Based on these results, optimizations with Simplex algorithm have been launched from the best samples obtained in the DOE in order to converge to the global minimum and to avoid the problem of local optima.

The three identified hardening laws from the biaxial test are compared with the experimental flow true stress-strain curve determined from an uniaxial test (Fig. 20). It can be concluded that the flow stress curves identified with Mises and Hill48 yield criteria are not in good agreement with the analytical flow stress curve from uniaxial tensile experiments. The curve identified with Mises criterion strongly underestimates the hardening of the material, whereas Hill48 criterion overestimates hardening for low strains (below 7\%) and underestimates for larger strains. As expected, due to the advanced formulation of Bron and Besson yield criterion, the flow stress curve identified with this criterion is very close to the uniaxial results below $20 \%$. Nevertheless, the biaxial test permits an accurate evaluation of hardening until an equivalent plastic strain of $30 \%$. As it can be seen in Fig. 20, very different hardening behaviours can be identified depending on the choice of the yield criterion. Considering the type of loading (biaxial), this result is rather logical and permits to validate the whole modeling of the plastic behaviour of the material thanks to an adapted choice of both yield criterion and hardening. In Fig. 19, three points corresponding to the stress-state at the central point of the cross specimen have been added for the three yield functions. As it can be seen on this figure, due to the slight out of synchronization in the two tensile forces on each axis of the cross specimen, the stress state obtained in the specimen center is not exactly biaxial but is almost the same for the three tested yield criteria. This is confirmed by the temporal evolution of the stress path presented in Fig. 21 through the $\sigma_{2} / \sigma_{1}$ ratio. The $\sigma_{2} / \sigma_{1}$ stress ratio evolution is not presented for the elastic part, since the same elastic behaviour is consider whatever the yield criteria. As it can be observed in Fig. 21, the material follows a quasiconstant path in the stress space. 


\section{ACCEPTED MANUSCRIPT}

Tab. 2 Identified parameters of the Voce's hardening law for the three yield criteria

\begin{tabular}{cccccc}
\hline \multirow{2}{*}{ Yield criteria } & $\sigma_{0}(\mathrm{MPa})$ & $K(\mathrm{MPa})$ & $n$ & \multicolumn{2}{c}{ Objective $\delta(\%)$} \\
\cline { 5 - 6 } & & & & $\delta\left(\varepsilon_{1}\right)$ & $\delta\left(\varepsilon_{2}\right)$ \\
\hline Mises & 147.72 & 329.65 & 1.352 & 10.12 & 10.88 \\
\hline Hill48 & 153.62 & 249.75 & 3.392 & 12.46 & 12.10 \\
\hline Bron and Besson & 138.2 & 326.5 & 2.513 & 7.19 & 16.09 \\
\hline
\end{tabular}

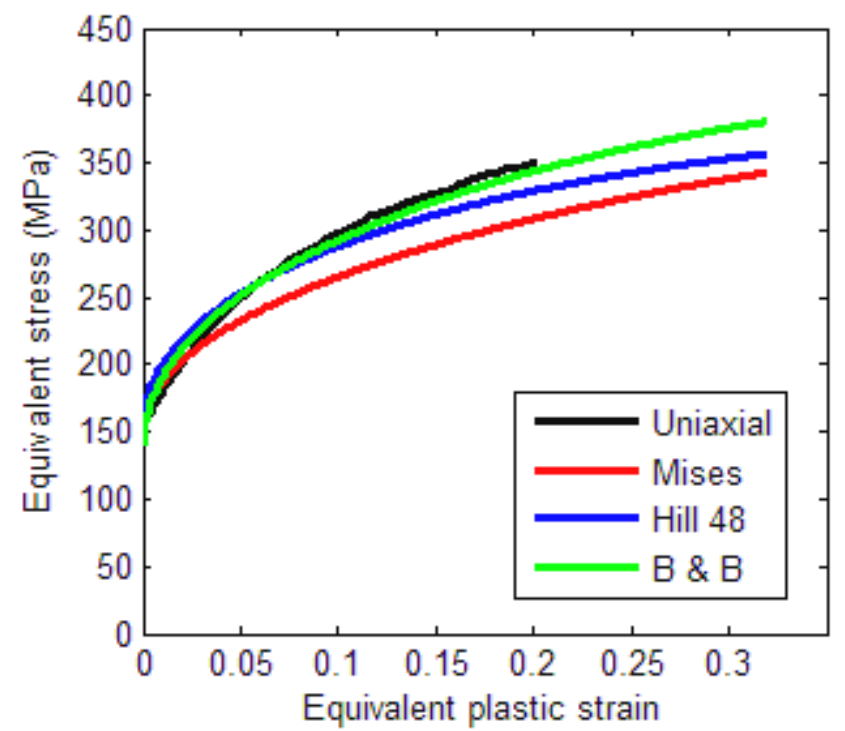

Fig. 20 Comparison of flow stress curves 


\section{ACCEPTED MANUSCRIPT}

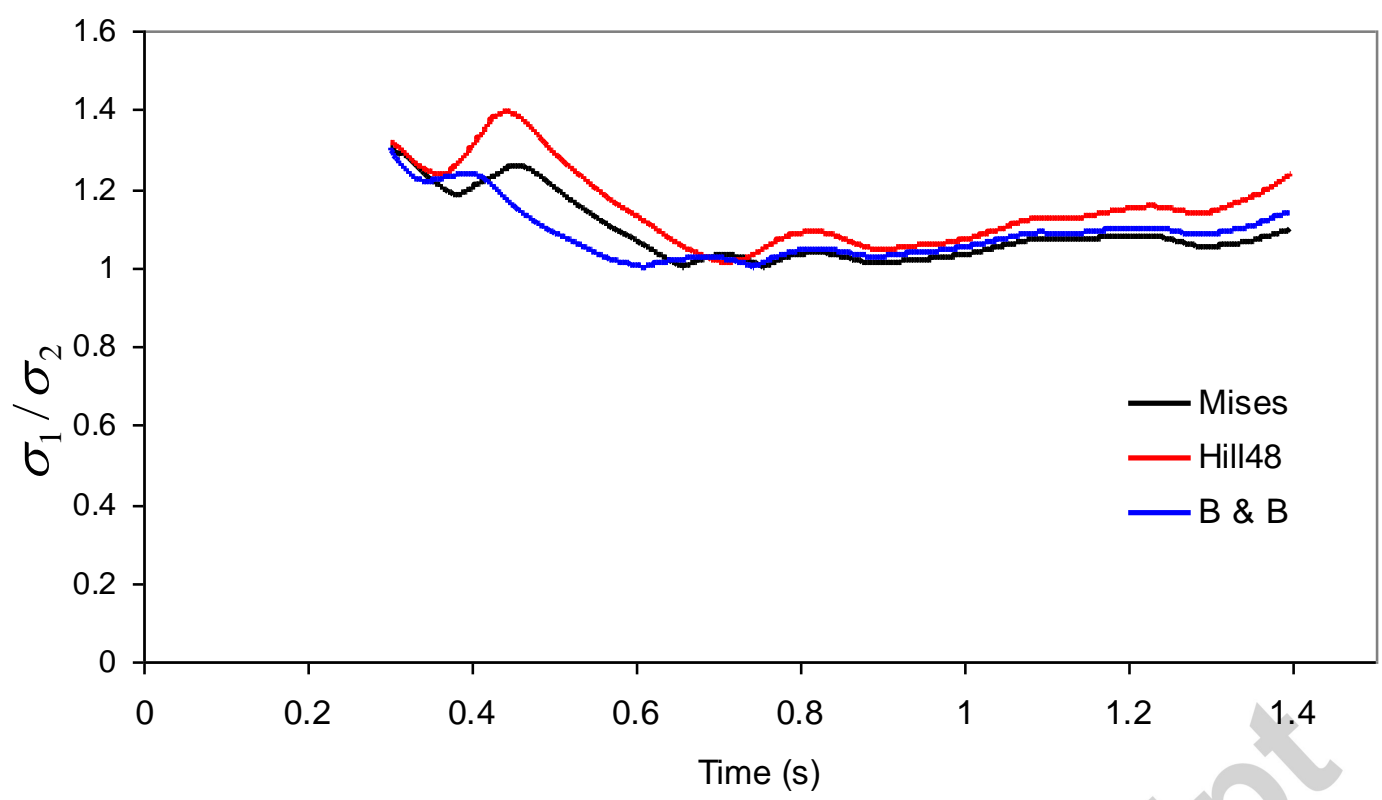

Fig. 21 Predicted $\sigma_{2} / \sigma_{1}$ ratio in the specimen central point for Mises, Hill48 and Bron and Besson yield functions

Based on the identified material models, the calculated principal strain curves are compared with the experimental ones in Fig. 22, Fig. 23 and Fig. 24, for Mises, Hill 48, and Bron and Besson 2004 yield criteria respectively. It can be seen that both Mises and Hill models do not describe properly the major strain evolution at the beginning of the test and up to $5 \%$ strain. For larger strains, Mises gives better results than Hill48. Those results are confirmed by values of cost function given in Tab. 2. For the simulation by the identified hardening law and the Bron and Besson 2004 yield criterion, the simulated major principal strain curve nearly coincide with the experimental one, while the simulated minor principal strain curves also coincide well with the experimental one until $8 \%$ minor strain. As expected, results from yield criterion of Bron and Besson give the best correlation with experimental evolutions of principal strains, especially at the beginning of the test. 


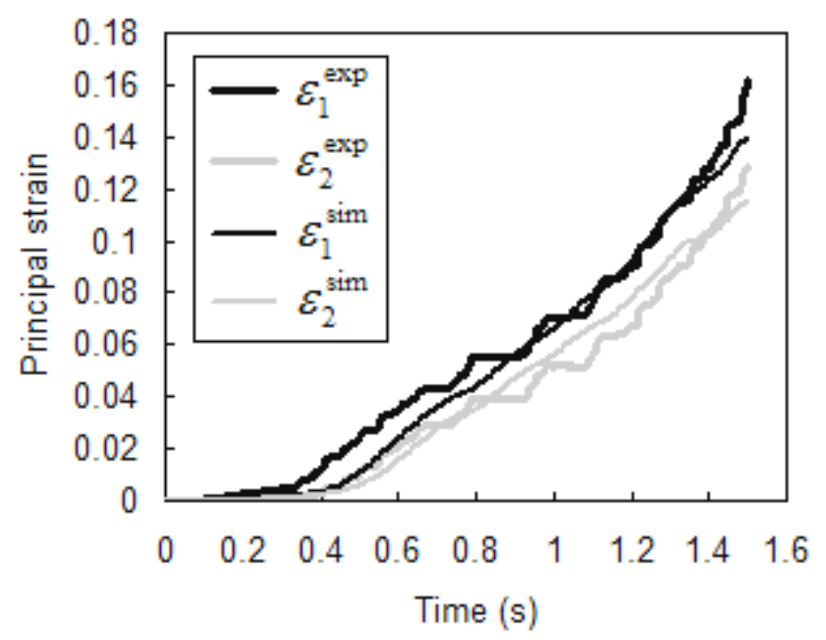

Fig. 22 Experimental and simulated (Mises) principal strains

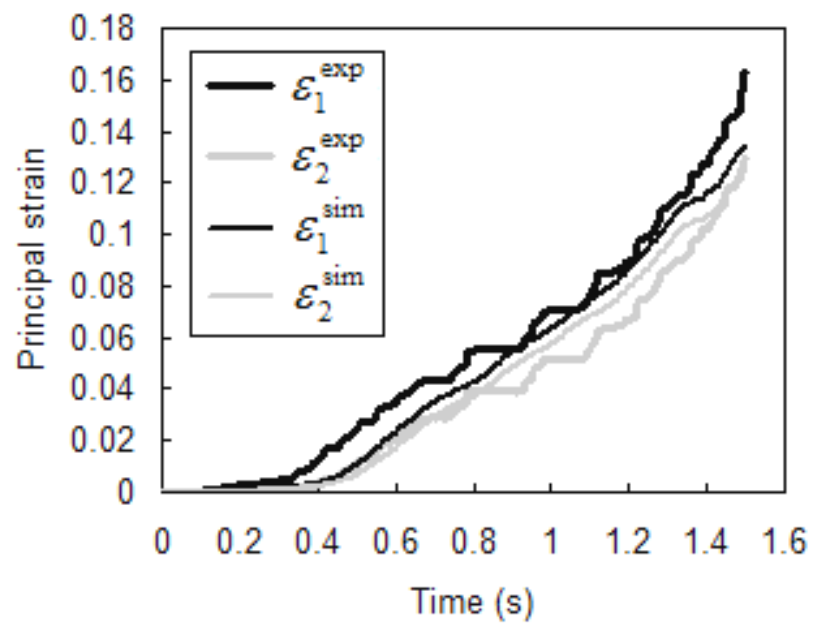

Fig. 23 Experimental and simulated (Hill48) principal strains

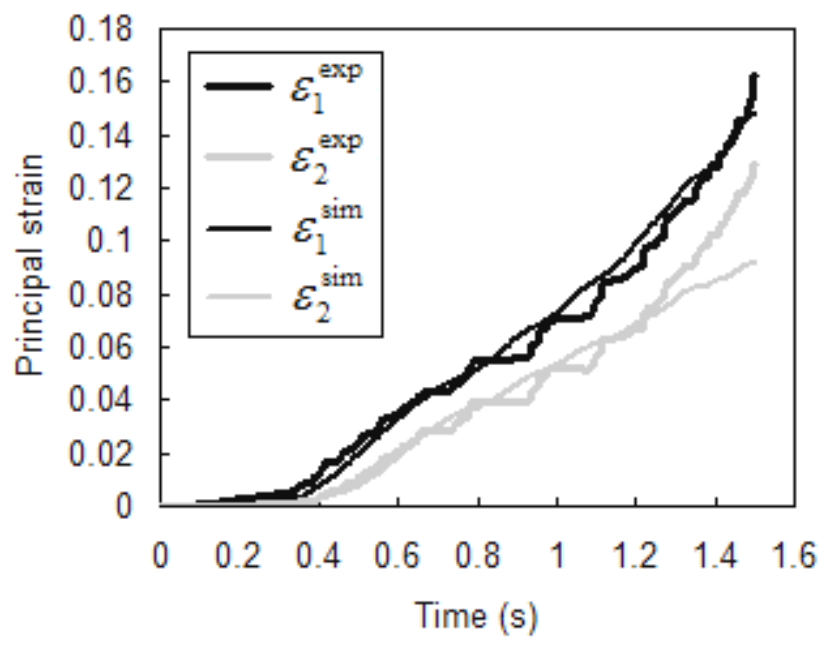

Fig. 24 Experimental and simulated (Bron and Besson) principal strains 
The strain path, at the cross specimen center, is presented Fig. 25, mainly for the plastic strain range. Experimental $\varepsilon_{2} / \varepsilon_{1}$ ratio cannot be evaluated precisely at the beginning of the test for small levels of strains. As it can be observed in the Fig. 25, due to the slight out of synchronization and to the anisotropy of the material, this experimental ratio is always inferior to one and quite constant (between 0.6 to 0.8 ) for time ranging from 0.6 to $1.5 \mathrm{~s}$.

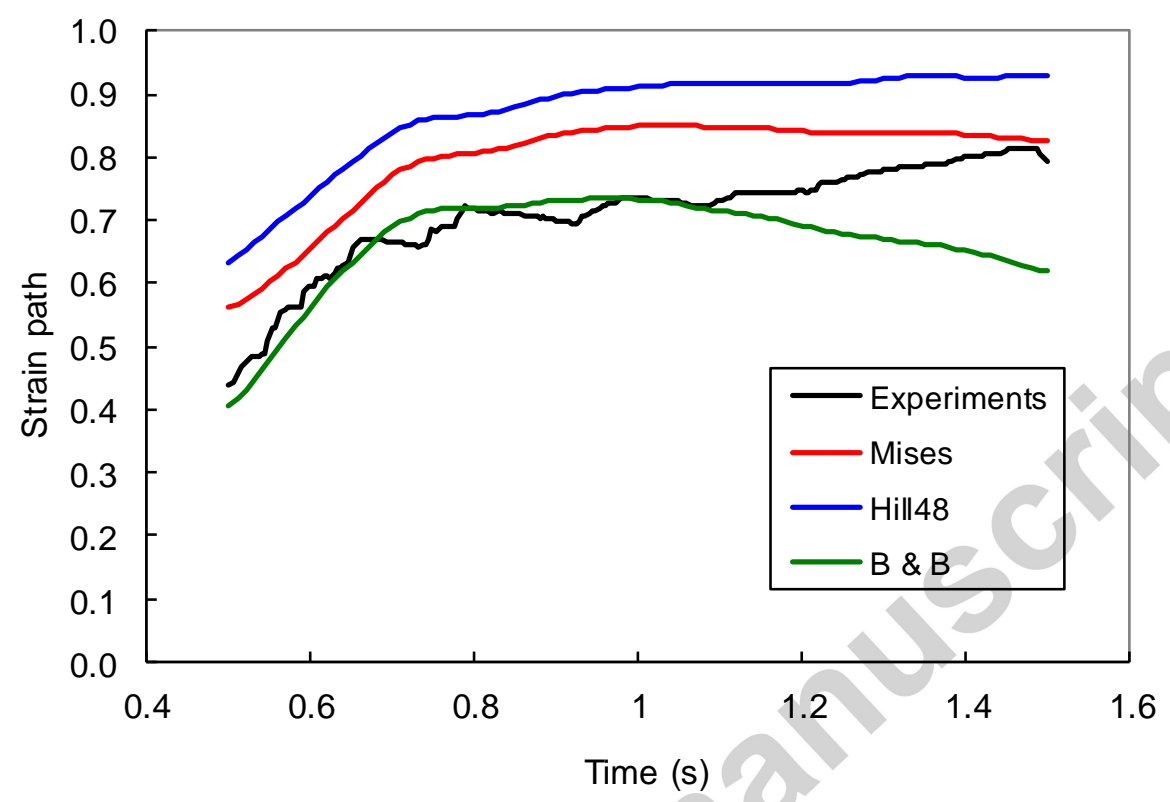

Fig. 25 Experimental and simulated strain path ratios

Concerning simulated strain paths, best agreement is obtained with the Bron and Besson criterion up to $1.2 \mathrm{~s}$, afterwards the $\varepsilon_{2} / \varepsilon_{1}$ ratio decreases. This effect is due to the divergent evolution of experimental and calculated minor strains as it can be observed in Fig. 24. The other two simulated strain paths from Mises and Hill48 criteria overestimate the $\varepsilon_{2} / \varepsilon_{1}$ ratio, more especially for the Hill48 criterion.

\section{Conclusion}

In this work, the potential of the in-plane biaxial tensile test on cross specimen to characterize the hardening behaviour of metallic sheets under large strains has been investigated. Due to the complex specimen shape, exhibiting non-homogeneous strain and stress fields, a numerical FE model of the biaxial tensile test used in an inverse calibration procedure is needed to identify constants of the hardening behaviour. To propose a simple 


\section{ACCEPTED MANUSCRIPT}

calibration stage of these hardening material constants, the strain evolution of the central point of the specimen is considered in the identification procedure.

The proposed cruciform specimen shape, with a constant thickness central zone, permits to reach an experimental biaxial flow stress curve for AA5086 up to 30\% of equivalent plastic strain. The identification strategy is based on both experimental local principal strains at the central point of the specimen and global force measurements along the two arms of the specimen. The hardening behaviour has been identified for both isotropic (Mises criterion) and anisotropic plastic criteria, a simple one (Hill48) and an advanced one (Bron and Besson).

Comparison between the identified biaxial flow stress curves and the experimental one from uniaxial tensile test (below 20\%), shows a good agreement if an appropriate yield criterion is considered. This is confirmed by the strain path in the center of the specimen which is better predicted by Bron and Besson yield function. Consequently, due to the biaxial loading, both the yield criterion and the hardening are validated for the modeling of the sheet material behaviour.

Like the bulge test, in-plane biaxial tensile test permits also the identification of hardening behaviour up to large strains. Nevertheless, contrary to the bulge test, strain path is controlled by actuator displacements in the two main directions of the cross specimen and effects of strain path changes can be investigated without any restriction about the type of non-linear path. This feature provides interesting perspectives for the identification of advanced hardening behaviours like isotropic-kinematical combined models. Strain rate dependent hardening sensitivity can be also studied by this procedure since the cross shape and the servo-hydraulic testing machine permit to reach intermediate strain rates (below $100 \mathrm{~s}^{-1}$ ) encountered in sheet metal forming processes.

\section{References}

[1] T. Meinders, E. Perdahcioglu, M. Riel, H. Wisselink, Numerical modeling of advanced materials, International Journal of Machine Tools \& Manufacture, 48 (2008) 485-498.

[2] G. Gutscher, H. Wu, G. Ngaile, T. Altan, Determination of flow stress for sheet metal forming using the viscous pressure bulge (VPB) test, Journal of Materials Processing Technology, 146 (2004) 1-7. 


\section{ACCEPTED MANUSCRIPT}

[3] T. Kuwabara, Advances in experiments on metal sheets and tubes in support of constitutive modeling and forming simulations, International Journal of Plasticity 23 (2007) $385-419$.

[4] An Y.G., Vegter H., Analytical and experimental study of frictional behavior in throughthickness compression test, Journal of Materials Processing Technology (2005) 160:148-155.

[5] Steglich D., Tian X., Bohlen J., Kuwabara T., Mechanical Testing of Thin Sheet Magnesium Alloys in Biaxial Tension and Uniaxial Compression, Experimental Mechanics (2014) 54:1247-1258.

[6] International Standard ISO16842, Metallic materials - Sheet and strip - Biaxial tensile testing method using a cruciform test piece, 2014.

[7] T. Kuwabara, S. Ikeda, K. Kuroda, Measurement and analysis of differential work hardening in cold-rolled steel sheet under biaxial tension, Journal of Materials Processing Technology, 80-81 (1998) 517-523.

[8] W. Muller, K. Pohlandt, New experiments for determining yield loci of sheet metal, Journal of Materials Processing Technology, 60 (1996) 643-648.

[9] T. Naka, T. Uemori, R. Hino, M. Kohzu, K. Higashi, F. Yoshida, Effects of strain rate, temperature and sheet thickness on yield locus of AZ31 magnesium alloy sheet, Journal of Materials Processing Technology 201 (2008) 395-400.

[10] M. Merklein, W. Hubnatter, M. Geiger, Characterization of yielding behavior of sheet metal under biaxial stress condition at elevated temperatures, CIRP Annals - Manufacturing Technology 57 (2008) 269-274.

[11] S. Avril, F. Pierron, Y. Pannier, R. Rotinat, Stress Reconstruction and Constitutive Parameter Identification in Plane-Stress Elasto-plastic Problems Using Surface Measurements of Deformation Fields, Experimental Mechanics 48 (2008) 403-419.

[12] M. Teaca, I. Charpentier, M. Martiny, G. Ferron, Identification of sheet metal plastic anisotropy using heterogeneous biaxial tensile tests, International Journal of Mechanical Sciences 52 (2010) 572-580.

[13] S. Zhang, L. Leotoing, D. Guines, S. Thuillier, Potential of the cross biaxial test for anisotropy characterization based on heterogeneous strain field, Experimental Mechanics, DOI 10.1007/s11340-014-9983-y.

[14] P. Prates, M. Oliveira, J. Fernandes, A new strategy for the simultaneous identification of constitutive laws parameters of metal sheets using a single test, Computational Materials Science 85 (2014) 102-120. 


\section{ACCEPTED MANUSCRIPT}

[15] D.E. Green, K.W. Neale, S.R. MacEwen, A. Makinde, R. Perrin, Experimental investigation of the biaxial behaviour of an aluminum sheet, International Journal of Plasticity 20 (2004) 1677-1706.

[16] C.C. Tasan, J.P.M. Hoefnagels, G. Quaak, M.G.D. Geers, In-Plane Biaxial Loading of Sheet Metal until Fracture, Proceedings of the XIth International Congress and Exposition, June 2-5, (2008) Orlando, Florida USA.

[17] F. Abu-Farha, L. Hector, J, M. Nazzal, On the Development of Viable Cruciform-Shaped Specimens: Towards Accurate Elevated Temperature Biaxial Testing of Lightweight Materials, Key Engineering Materials Vol. 433 (2010) 93-101.

[18] Y. Yu, M. Wan, X. Wu, X. Zhou, Design of a cruciform biaxial tensile specimen for limit strain analysis by FEM, Journal of Materials Processing Technology 123 (2002) 67-70.

[19] I. Zidane, D. Guines, L Leotoing, E. Ragneau, Development of an in-plane biaxial test for forming limit curve (FLC) characterization of metallic sheets, Measurement Science and Technology 21 (2010) 1-11.

[20] L. Leotoing, D. Guines, I. Zidane, E. Ragneau, Cruciform shape benefits for experimental and numerical evaluation of sheet metal formability, Journal of Materials Processing Technology 213 (2013) 856-863.

[21] S. Cooreman, D. Lecompte, H. Sol, J. Vantomme, D. Debruyne, , Exp. Mech. 48 (2008) $421-433$.

[22] J. Dupré, P. Dumoulin, V. Valle et al., Mode d'emploi du logiciel CORRELA 2006, Université de Poitiers, 2006.

[23] P.Y. Manach, S. Thuillier, J.W. Yoon, J. Coër, H. Laurent, Kinematics of Portevin-Le Chatelier bands in simple shear, International Journal of Plasticity 58 (2014) 66-83.

[24] ModeFrontier ESTECO, http://www.esteco.com/modefrontier.

[25] F. Bron, J. Besson, A yield function for anisotropic materials - Application to aluminum alloys, International Journal of Plasticity 20 (2004) 937-963.

[26] S. Zhang, L. Leotoing, D. Guines, S. Thuillier, S.L. Zang, Calibration of anisotropic yield criterion with conventional tests or biaxial test, International Journal of Mechanical Sciences 85 (2014) 142-151.

[27] S. Diot, D. Guines, A. Gavrus, E. Ragneau, Forming process of a 5083 aluminium alloy: constitutive model covering a large range of temperature, International Journal of Forming Processes 9 (2006) 167-188. 


\section{ACCEPTED MANUSCRIPT}

[28] I. Zidane, Développement d'un banc d'essai de traction biaxiale pour la caractérisation de la formabilité et du comportement élastoplastique de tôles métalliques, Thèse de doctorat, INSA de Rennes, 2009.

Highlights

- Experimental in-plane biaxial tensile tests

- Identification of sheet metal hardening under large strains

- A dedicated flat cruciform specimen shape for large strains has been proposed

- Considering three different yield criteria, the Voce's hardening law has been identified 